


\title{
ECONOMIC CONVERGENCE AND THE GLOBAL CRISIS OF 2008-2012: THE CASE OF BALTIC COUNTRIES AND UKRAINE
}

\author{
Andrii VERSTIAK \\ Chernivtsi National University, Ukraine, Department of Economics \\ Kotsubinsky Chernivtsi, Ukraine \\ E-mail: a.verstyak@chnu.edu.ua
}

Oksana VERSTIAK

Chernivtsi Institute of Trade and Economics, Department of International Economics

E-mail: oks1982@gmail.com

\section{Olena PITYK}

Chernivtsi Institute of Trade and Economics, Department of Finance

E-mail: olenkasonet@mail.ru

doi:10.13165/IE-14-8-2-10

\begin{abstract}
The sustainable economic welfare of the new EU Member States is reflected in the convergence process. The paper is dedicated to the investigation of the convergence between Ukraine, Baltic countries and other EC countries within the various indices of the social-economic development. The system of economic growth models is analyzed: the convergence is theoretically grounded on the basis of Solow model, and thus the methods of empiric control of convergence concept are determined. The empiric analysis of convergence processes between above mentioned countries showed that the most spreading method of convergence presence in the rate of economic growth is the reduction of the inequality in the GDP per capita level among the countries groups.
\end{abstract}

JEL classification: F15, O47. 
Keywords: global crisis, economic convergence, $\beta$-convergence, $\sigma$-convergence, divergence, international integration, foreign (external) trade, integration processes, Baltic countries, Ukraine.

\section{Introduction}

The history of European integration gives the evidence that it occurred among the countries achieving relatively high levels of economic and political development. The integration (apart from the reasoned process of increasing interdependence of national economies) is based on the need for mutual adaptation and the joint regulation of economic processes across the entire economic complex formed. The effectiveness of this regulation depends on the level of economics, social and legal systems. Further increasing of the integration participants requires certain reforms of established structures that directly reflected in the process of such integration. New countries in integration associations enlarge the role and pressure on the governing bodies. From the beginning, the whole mechanism of the EU aimed to help less developed countries and regions to achieve a more advanced level, i.e. to ensure economic convergence. Creating the conditions for economic convergence is crucial for the existence of the integrated association. Thus, it sets the extension limit of the integration association, which is due to economic efficiency.

In the theory of economic growth, there is assumed that the initial differentiation in the level of economic development is the result of exogenous shocks and imperfect adjustment mechanisms. In accordance with the hypothesis of convergence, if the economy of the country (region) at the initial point is further from the position of stable equilibrium, its growth rate will be higher than in the economy, which is closer to equilibrium. So, in the long-term period the differentiation disappears. Above mentioned processes are of the higher interest during the crisis period when detrimental trends may have significant effects on economic policies facilitating potential growth. The paper considers convergence and catchup process during the continuous crisis and in terms of these the main economic growth trends.

\section{Facts, theory, data, and methodology}

The analysis of the researches devoted to convergence process (Barro, Sala-i-Martin, 1991, 1992, 1995, 2004; Le Pen, 2005) allowed distinguishing the following basic mechanisms that provide a positive impact on such process: 
Figure 1: The convergence mechanisms

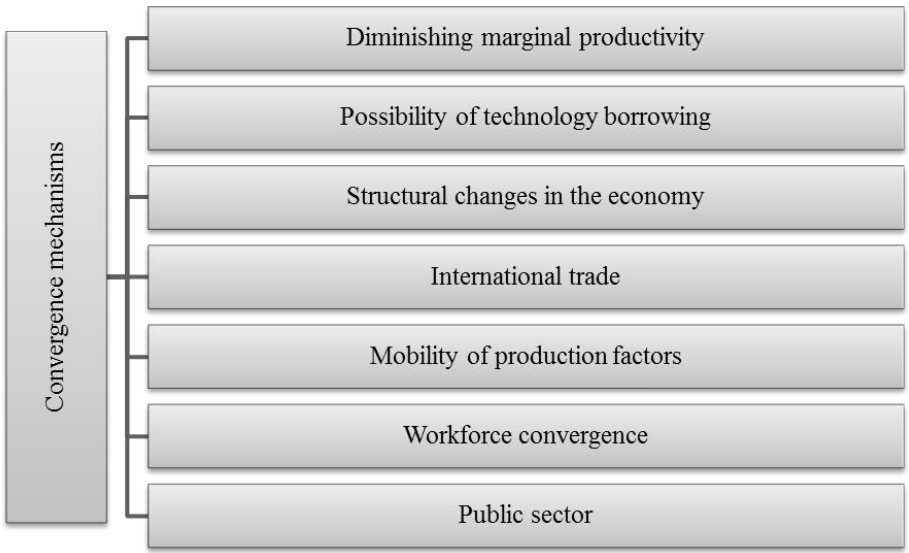

Source: Barro, Sala-i-Martin, 1991, 1992, 1995, 2004; Le Pen, 2005

In the theory of economic growth, the most common hypothesis of convergence is used to study the dynamics and differences in the level of GDP (GRP) per capita. Accordingly it is of high importance to analyse above mentioned trends in Baltic countries and Ukraine. Before the crisis period examined economies showed significant growth and on the other side - the highest decline of GDP in 2009 (Fig. 2).

Figure 2: Real GDP growth, \% to previous year

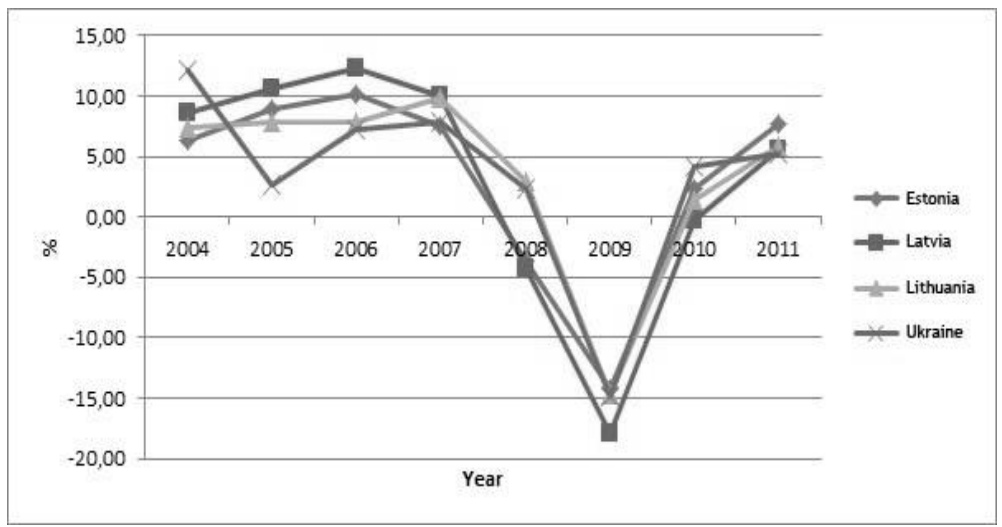

Source: Eurostat (2012); Ukrstat (2012) 
In the period from 2000 to 2007 Baltic countries and Ukraine experienced significant real GDP growth, sometimes above $10 \%$ per annum (GDP growth peaked in all investigated countries across the interval 2006-2007), however, the country experienced strong declines in 2009: the main impacts on output growth significantly changed during this period. A deeper analysis in Fig. 3 shows the change in real GDP in 2009 in all EU Member States and Ukraine.

Figure 3: Real GDP growth, \% to previous year



Source: Eurostat (2012); Ukrstat (2012)

The highest rate of decline of real GDP is held in the investigated countries: Latvia, Lithuania, Estonia and Ukraine (Fig. 2). Thus, there is a significant gap between other countries: Estonia $-14.26 \%$, and the nearest (in terms of decline in GDP) Romania $-8.5 \%$. It should also be noted that Poland is the only country in which there is an increase in output growth during the crisis period. There is a thought that such situation was provided due to European Football Championship 2012, resulting in economic "acceleration".

Comparing the trends of crisis in the Baltics and Ukraine with other countries, it may be noted that it was V-shaped (Fig. 1), that decline was as steep as the further rise, while, in particular, Portugal and Greece are in recession long enough.

The above analysis of real GDP trends represents the convergence process between these countries. However, it should be noted that in the literature there is no single definition of "convergence" and it is mentioned several convergence concepts hypothesis. The most 
widely used two concepts of convergence: the so-called beta-and sigma-convergence (Barro, Sala-i-Martin, 1991, 1992, 1995, 2004; Le Pen, 2005).

The concept of $\beta$-convergence (Barro, Sala-i-Martin, 1991) defines convergence as a process of "building" in which countries with lower levels of development have higher rates of economic growth. The second type of convergence, i.e., $\sigma$-convergence (Barro, Sala-iMartin, 1992), defined as a reduction in the time variance of the GDP distribution or another indicator of income in countries or regions. The hypotheses of $\beta$-convergence and $\sigma$ convergence are interdependent, but not equivalent. A number of studies (Barro, Sala-iMartin, 1991, 1992, 1995, 2004) proved that with absolute $\beta$-convergence $\sigma$-convergence does not follow directly. Henin and Le Pen (1994) suggested the interpretation of interdependence between two types of convergence: absolute $\beta$-convergence indicates the existence of the trend towards reducing the gap in GDP per capita. At the same time, random shocks affecting the economy of countries (regions) may counteract this trend and temporarily increase the variance of the distribution of GDP per capita.

The starting point for the analysis of convergence is the so-called unconditional $\beta$ convergence model, which is based on the neoclassical theory of growth (Solow, 1956, 1957). Within this model the economic growth is positively correlated with a gap at the initial time between initial per capita income for the country (region) and the level of per capita income in the steady state equilibrium (steady-state level), which are the same for all regions. In steadystate equilibrium countries, (regions) have a stable growth path, characterized by the constant growth rate of per capita income. In compliance with the model countries (regions) with lower development should grow at a faster rate than those with higher levels of development, so in the long-term period it should be aligning of regional levels of economic development. The model of unconditional $\beta$-convergence can be written as (Barro, Sala-i-Martin, 1992):

$$
g_{T}=\alpha+\beta y_{0}+\varepsilon, \varepsilon \square N\left(0, \sigma^{2} I\right),
$$

where $g_{T}$ - logarithm of the average growth rate for the period $T ; y_{0}$ - logarithm of the initial level of (GDP per capita); $\alpha$ - parameter that contains a provision for technological progress and the level of per capita income in the steady state equilibrium; $\beta$-rate of convergence; $\varepsilon$-random component.

The process of convergence is characterized by "convergence speed" and by overcome time of half the distance that separates the economy of the country (region) from its steady state. These coefficients can be calculated by evaluating the coefficient of convergence $\beta_{\text {as }} \hat{b}=-\ln (1-T \hat{\beta}) / T$ and $h l=\ln (2) / \hat{b}$, respectively. The convergence rate 
is determined by the sign and value of the coefficient $\beta$. If $\beta<0$, so there is convergence; if $\beta>0$, then there is divergence. In the model of unconditional convergence in accordance with neoclassical growth theory it is tested the hypothesis of a negative correlation between average growth rate and initial per capita income (Barro, Sala-i-Martin, 1992). At the same time, the theory assumes that countries (regions) tend to a single trajectory of proportional growth.

Let us note that in model (1) the investigated countries (regions) rather homogeneous in economic structure and characterized only temporal differences in levels of economic development, which are explained by differences in initial levels of per capita income. It is logical to assume that different countries (regions) have different trajectories proportional growth and, consequently, different long-term growth. In this case, the alignment of economic development of countries (regions) cannot occur. The objective of regional policy, in this case, is the adoption of such tools that can raise the equilibrium level of sustainable growth states of underdeveloped regions.

We turn our attention to the methodology of empirical evidence of convergence concept. The most common statistical method to check $\beta$-convergence is the regression rate of GDP growth on a constant and the logarithm of initial GDP per capita. If the coefficient of the explanatory variables is statistically significant, then there is the negative of its value, so the hypothesis of absolute convergence is not rejected. However, there are some problems with the econometric estimation resulting in biased estimates of the coefficient $\beta$. In particular, the variance $\log \left(y_{i, t}\right)$ will respond to shocks that have a common effect on the group of countries or regions resulting in a violation of the assumption that the shocks $u_{i, t}$ are independent of different countries. In this case, such shocks will positively or rather negatively act in the countries (regions) with high or low income, so the estimation of the coefficient $\beta$ in regression analysis will be shifted. To solve this problem, it can be included additional variables that characterize the effect of certain shocks. Provided independent variable of initial income level of the country or region and additional variables, the econometric evaluation of coefficient $\beta$ will be meaningful.

In empirical studies on this issue, there are attempts to evaluate the hypothesis of convergence for various countries and regions for the same country. In particular, Barro and Sala-i-Martin in their book (Barro, Sala-i-Martin, 2004) suggest the assessment of $\beta$ convergence for the period 1880-2000 in the United States from the equation:

$$
\left(\frac{1}{T}\right) \ln \left(\frac{y_{i, T}}{y_{i, 0}}\right)=a+\left[\frac{\left(1-e^{-\beta T}\right)}{T}\right] \ln \left(y_{i, 0}\right)+\omega_{i 0, T} .
$$


Estimates were done throughout the period, as well as some sub-periods showed the presence of convergence between different states. Estimates of the coefficients $\beta$ at several periods were negative, but after introduction control variables, that reflect the geographical location of the structural shocks, all coefficients were positive and statistically significant. In general, it was concluded that the rate of convergence between the different states is about $2 \%$ per year.

Similar reviews were conducted according to prefectures in Japan for the period 19301990. The estimates also showed the presence of $\beta$-convergence: the $\beta$ ratio was about 0,028 . Estimates of the coefficient $\beta$ for some sub periods with the negative sign turned positive after inclusion the structural variables. Barro, Sala-i-Martin (2004) also performed estimation of the convergence according to the 90 regions in 8 European countries for the period from 1950 to 1990 (11 in Germany and the UK, 20 in Italy, 21 in France, 4 in Holland 3 - in Belgium, 3 in of Denmark and 17 in Spain). Unlike the U.S. and Japan, for the estimation of interstate differences it was included state logic variables in the initial regression. The level of $\beta$ convergence was about 0,02 . In this case, the coefficient $\beta$ could vary for different countries, but did not change over time. Estimated values ranged from 0,012 (France) to 0,027 (UK).

The concept of $\sigma$-convergence is based on the analysis of changes in GDP per capita, that is if, $\sigma_{t+T}<\sigma_{t}$, (where $\sigma_{t}$ - appropriate statistical performance); then there is $\sigma$ convergence. To test the concept of $\sigma$-converging we can use the following statistical characteristics: range of deviation; mean deviation; dispersion; standard deviation; coefficient of variation.

The empirical evidence of the $\sigma$-convergence concept focuses on the dynamics of the statistical performance distribution of GDP per capita logarithms. Accordingly, if a sample of countries (regions) variance distribution of GDP per capita logarithms decreased from the beginning to the end of the test period, $\sigma$-convergence hypothesis is not rejected. Such a method of the testing this hypothesis is purely descriptive. In particular, Lichtenberg (2004) modified Fisher test to check whether a reduction in variance from the beginning to the end of the period statistically significant. For the above countries (USA, Japan, Europe) the estimation of $\sigma$-convergence was also done: the results of $\beta$-and $\sigma$-convergence analysis for the considered groups of countries or regions fully meet each other. In order to test the validity of the $\sigma$-convergence hypothesis, we can also use other indicators showing the per capita income. In particular, along with indicators of variance or standard deviation in some studies it is used the coefficient of variation, which is the ratio of the square root of the variance to the sample average. Moreover, it can be used the weighted coefficient of variation, which is calculated in the standard way, but takes into account the weighted average indices and dispersion.

The period of the settlement in our research - Q1 2002-Q2 2012. With the purpose of the detailed analysis of the crisis impacting on converging the period is divided into three sub periods: 
1) pre-crisis period: Q1 April 2002- Q3 April 2008 (a division associated with the bankruptcy of Lehman Brothers on September 15, 2008 and the global financial crisis);

2) the period before the European debt crisis: Q4 April 2008- Q4 April 2009 (i.e. before the government bonds crisis in Greece);

3) the progress of the European debt crisis: Q4 2009-Q2 2012.

\section{Empirical results}

Estimation of $\sigma$-convergence

Estimation results of the above statistical characteristics had given similar results. Therefore, we turn our attention on a detailed investigation of the main one - the coefficient of variation (the results of calculation of other indicators cab be sent by authors upon request). The calculated values of the coefficient of variation for the entire study period and for sub periods entered depicted in Fig. 4.a-4.d.

Figure 4: The changes of coefficient of variation

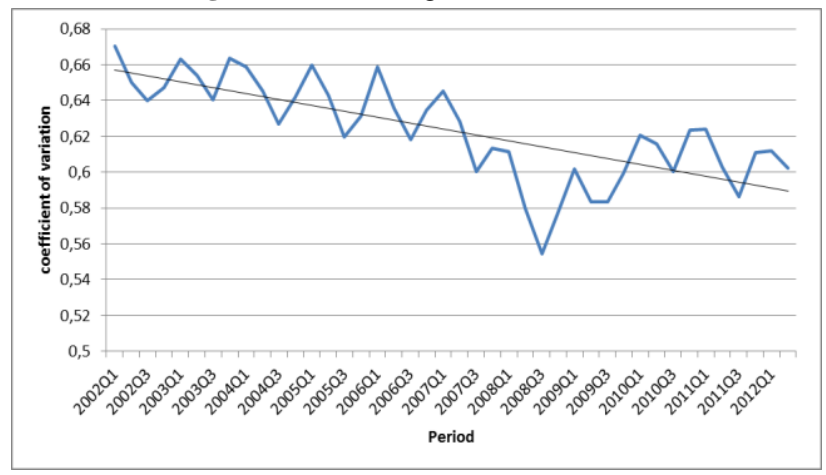

a (overall period)

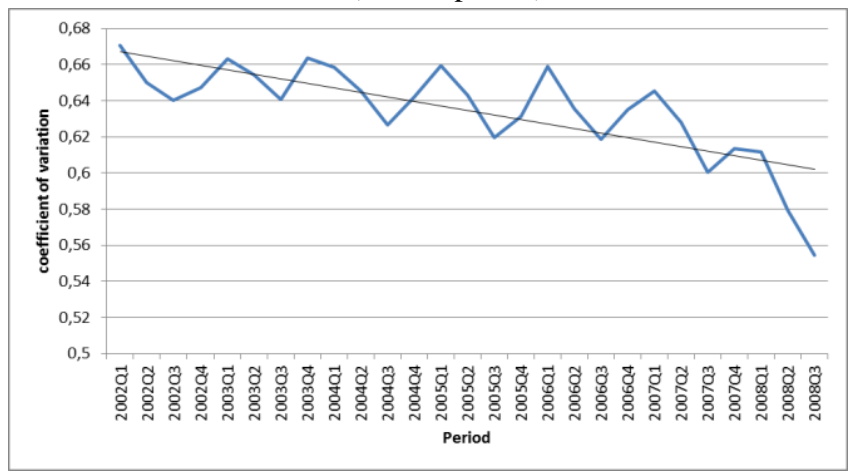

b (first sub-period) 


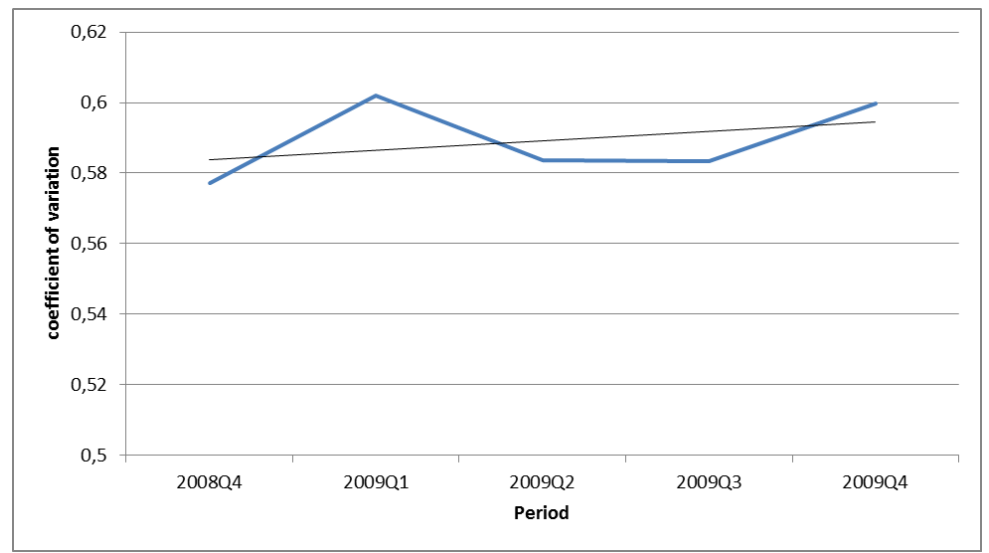

c (second sub-period)

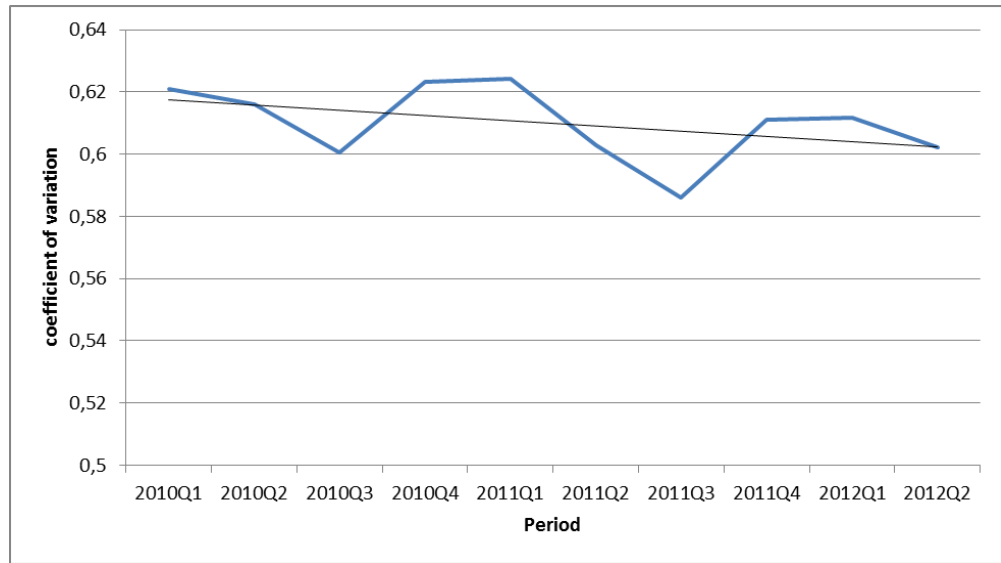

d (third sub-period)

Source: calculated by authors

For easier analysis, the graphs are based on the trendline that is used to identify trends. Basing on the analysis of Fig. 4.a we can conclude that $\sigma$-convergence across the overall period exists as we see the reduction of the coefficient of variation in time. However, according to Fig. 4.a, it can be seen a clear trend of the "different" behavior of the correlation coefficient in some sub periods. The coefficient of correlation in the pre-crisis period reflects the general trend towards convergence in the EU and Ukraine, as in many works for other regions (Fig. 4.b). Fundamental changes occurred after the starting point of the global financial crisis in 2008: there is observed the divergence in GDP growth between the EU and Ukraine (Fig. 4.c). 
In the crisis period the successful functioning of economic and monetary union of the EU was disrupted that is extremely important to achieve a high degree of sustainable convergence in the form of presence in all economies of low inflation, effective public sector, as well as the stability of the currencies. The convergence process intensified somewhat during the European debt crisis (Fig. 4.d). However, such processes are less impetuous: reducing of the coefficient of variation is scarce, and therefore it can be said about the lack of both convergence and divergence and the fact of stagnation in developing countries.

Summarizing the results, the overall conclusion is that the processes of $\sigma$-convergence between the EU (since. Baltic states) and Ukraine exist in the conditions of the absence of financial shocks - a level of inequality in such a period declines rather than increases. The global financial and economic crisis and European debt crisis significantly affect the investigated process and therefore in such periods there is the phenomenon of divergence. In other words, during the crisis the country is away from its steady-state level.

\section{Estimation of $\beta$-convergence}

As noted above, the assessment rate and the speed of convergence are based on the usage of econometric methods, so taking into account (1) regression equation has the form (for the entire period):

$$
\left(\frac{1}{T}\right)\left(\ln y_{i T}-\ln y_{i 0}\right)=0,089-0,0095 \ln \left(y_{i, 0}\right)+\varepsilon_{i},
$$

i.e. the rate of convergence $b=-0,0095$. Convergence rate is -0.008 , i.e. reducing the annual gap between countries was maintained at the level $0,8 \%$ per year, which is relatively low compared with similar calculations of other researchers (e.g., in the works of Barrow and Sala-i-Martin, estimated rate of convergence constituted 2-3\% per year; with such a convergence the gap will decrease by half in about 35 years). In other words, a country, that had the lower level of development in 2002 , increased by $0,8 \%$ faster than the country where the same coefficient was higher. Since $b<0$ and $\beta<0$, we can conclude about the existence of the convergence phenomenon between EU and Ukraine. The changes in the logarithm of GDP per capita for the period Q1 2002 - Q 22012 are shown in the Fig. 4.

So we can see which countries have lower levels of socio-economic development and, therefore, will in the future develop faster than more developed countries: Ukraine, Slovakia and the Baltic states (it should be noted that the sample does not include Bulgaria and Romania due to the lack of statistical quarterly data of GDP per capita). This situation explains somewhat the same impact of the crisis on the investigated countries. The results for the sub periods are the same as for $\sigma$-convergence concept. 
Figure 4: The changes of coefficient of variation (Q1 2002 - Q 2 2012)



Source: calculated by authors

Thus, the economic dependence of emerging countries from developed countries is primarily manifested in the fact that developed countries are net exporters of capital in developing countries, while developing countries are, in fact, their debtors. The economic dependence of these countries, as well as a lower level of economic development, has its concrete manifestations. First, the "new" countries are directly dependent on the sales of its raw materials on world markets. Secondly, foreign capital has a significant presence in the economy of the most of these countries. That is why during the crisis, imbalances between countries with different levels of socio-economic development only increases.

\section{Conclusion}

Thus, convergence process in the crisis period goes back due to the following reasons:

1) inability to achieve a high degree of inflation stability;

2) changing of the financial market stability, which is determined by the relationship between the real economy and the impact that has financial markets on economic growth and, ultimately, on the level of convergence of Ukraine and Baltic countries;

3) negative change rate of the national currency;

4) inability of effective government regulation at all levels;

5) intensification of financial markets globalization and integration and the development of financial infrastructure based on modern technology: financial globalization 
has increased the influence of international markets for lending and borrowing operations in different countries.

\section{References}

1. Barro R.J, Sala-i-Martin, X. (2004) Economic Growth. Cambridge, Massachusetts; London, England, MIT Press.

2. Barro R.J, Sala-i-Martin, X. (Ed.) (1991). Convergence across states and regions. Brookings Papers on Economic Activity, 1, 107-158.

3. Barro, R. J. and Sala-i-Martin, X. X. (1992). Convergence. Journal of Political Economy 100, 223-251.

4. Barro, R.J., Sala-i-Martin, X.X. (1995). Economic Growth. McGraw Hill, New.

5. Henin, P.Y. and Le Pen, Y. (1995). Les episodes de la Convergence Europeenne. Revue Economique, 46 3, pp. 667-677.

6. Lichtenberg, Frank R. (1994). Testing the Convergence Hypothesis. Review 76, $576-579$.

7. Solow, Robert. (1956). A Contribution to the Theory of Economic Growth. Quarterly Journal of Economics, 70, 65-94.

8. Solow, Robert M. (1957). The Technical Change and the Aggregate Production Function. Review of Economics and Statistics 39:312-320.

9. Yannick Le Pen. (2005). Convergence among five industrial countries (18701994): Results from a time varying cointegration approach. Empirical Economics vol. 30(1), pages 23-35, January. Springer.

\section{About the Authors:}

Andrii Verstiak - Chernivtsi National University, Ukraine, Department of economics, Phd., Associate professor. Research interests: mathematical and quantitative methods in environmental economics.

Oksana Verstiak - Chernivtsi Institute of Trade and Economics, Ukraine, Department of international economics, Phd., Associate professor. Research interests: international economics, EU integration, economic and trade convergence in EU.

Olena PITYK - Chernivtsi Institute of Trade and Economics, Ukraine, Department of finance Research assistant. Research interests: Baltic countries, crisis period, financial contagion. 